Proc. Indian Acad. Sci. (Earth Planet. Sci.), Vol. 105. No. 1, March 1996, pp. 17-29.

(c) Printed in India.

\title{
Some observations from the data taken in and around Kharagpur during the onset of the monsoon, 1990
}

\author{
R PRADHAN, B ROY, U K De and D K RAKSHIT \\ Department of Physics, Jadavpur University, Calcutta 700032, India
}

\begin{abstract}
During MONTBLEX 1990, various observational platforms were operated at Kharagpur and the nearby Kalaikunda Air Base. Using the data from all the platforms, one can draw the following conclusions. The temperature and wind data obtained from various sensors have overall compatibility. Sodar wind data indicate the presence of a low level jet at around $300 \mathrm{~m}$ above ground. The inversion height may be evaluated fron the vertical profile of the sodar back-scatter echo intensity. The sub-synoptic or synoptic scale convergence modulates the inversion height and the presence of cloud-base within the inversion height in turn modulates the sensible heat and momentum fluxes.
\end{abstract}

Keywords. Boundary layer; inversion height; back-scatter intensity; surface parameters; convective instability; low level cloud-base height.

\section{Introduction}

In terms of global balance of energy, the surplus energy of the tropical region is transported from the surface of the earth to the upper atmosphere through two distinct processes, i.e., by radiation and by convection. In the process of convection eddy diffusion plays a decisive role, and occurs through the boundary layer. This diffusion (in the vertical direction) is controlled by the corresponding thermal as well as wind profiles over the region. In reality, the boundary layer influences the overall atmosphere to a great extent through parameters like the vertical gradients of potential temperature and the wind velocity.

In the present work the data generated at Kharagpur $\left(22^{\circ} 18^{\prime} \mathrm{N}, 87^{\circ} 12^{\prime} \mathrm{E}\right)$ observational station and that supplied by the nearby Kalaikunda (KLK) Air Base ( 3 to $4 \mathrm{~km}$ away from Kharagpur tower site) are utilized. At Kharagpur, a $30 \mathrm{~m}$-high micrometeorological tower with six levels of instrumentations (at heights 1, 2, 4, 8, 15, and $30 \mathrm{~m}$ ) was erected. Besides, other observational facilities like an Aerovironment-make 3-axis, monostatic Doppler Sonic Detection and Ranging (sodar) system and some flights of a tether sonde were available. Surface and upper wind data and cloud-base heights observed with the help of a laser ceilometer were collected at the Kalaikunda Air Base and these data were also available.

In the present study, however, attention is confined to the monsoon onset phase only. The nature of the boundary layer during the onset phase is expected to be interesting, especially over a deep moist convective region like Kharagpur. The monsoon onset phase at Kharagpur in 1990 was June 1st -17 th.

First, we have utilized all available data during the period June 4th - 9th at Kharagpur and Kalaikunda to sketch the thermal and dynamical vertical structure from the surface up to the maximum available height. Simultaneous data from all the 
above-mentioned sources were available only during the period June 4 th -9 th. It has been found that the vertical profile of horizontal wind velocity components and temperature available from the various sources have overall compatibility.

Second, the vertical profiles of back-scatter echo intensity from the sodar system are presented for various times. In ten out of twelve cases, the inversion height supplied by the sodar coincides with the first peak in back-scatter echo intensity profile, but in two cases the coincidence is better with the second peak. Lastly, the time series for the surface parameters like sensible heat flux and momentum flux have been constructed for the period June 4th -9 th. The base of low level cloud supplied by a laser ceilometer at Kalaikunda Air Base has been correlated with the inversion height supplied by the sodar. It has been observed that the sensible heat flux shows a high value whenever the base of the low level cloud overhead lies within the inversion height or a wind convergence appears either in synoptic or sub-synoptic scales.

\section{Data}

The following sets of data are utilized in the present study.

\subsection{Data from $30 \mathrm{~m}$ micrometeorological tower located at the IIT campus of Kharagpur}

The instrumented tower had both slow as well as fast response sensors. In the present work, only 3-minute averaged slow response data available from MONTBLEX data bank are directly uşed.

\subsection{Data from tether-sonde (kytoon) flights}

The Atmospheric Instrumentation Research Inc. (USA)-make kytoon was flown at Kharagpur. Such flights could be accomplished only from the end of May 1990 to the end of June 1990. Altogether 29 flights were taken, out of which 20 were in the morning hours (between 0500 IST and 0600 IST) and the rest were in the afternoon hours (between 1400 IST and 1600 IST).

On an average the kytoon reached a height of about $350 \mathrm{~m}$ above ground, but on a few occasions it soared much higher. One of the reasons for its low level operation was the high wind conditions prevailing over Kharagpur during the month of June (Roy 1994).

Basic parameters like temperature, wind velocity, wind direction, relative humidity and the pressure heights were sensed directly by a data acquisition system attached to the kytoon.

\subsection{Data from acoustic sounder or sodar}

The 3-axis monostatic Doppler sodar operated during the MONTBLEX period has a sounding height ranging from $60 \mathrm{~m}$ to $1500 \mathrm{~m}$; operation times were from 0530 IST to 1230 IST and again from 1430 IST to 1930 IST. However, during the intensive observation periods the sodar was operated for 24 hours. The sodar mostly provided the hourly averaged data, but in some cases 30 -minute average data were also available. 


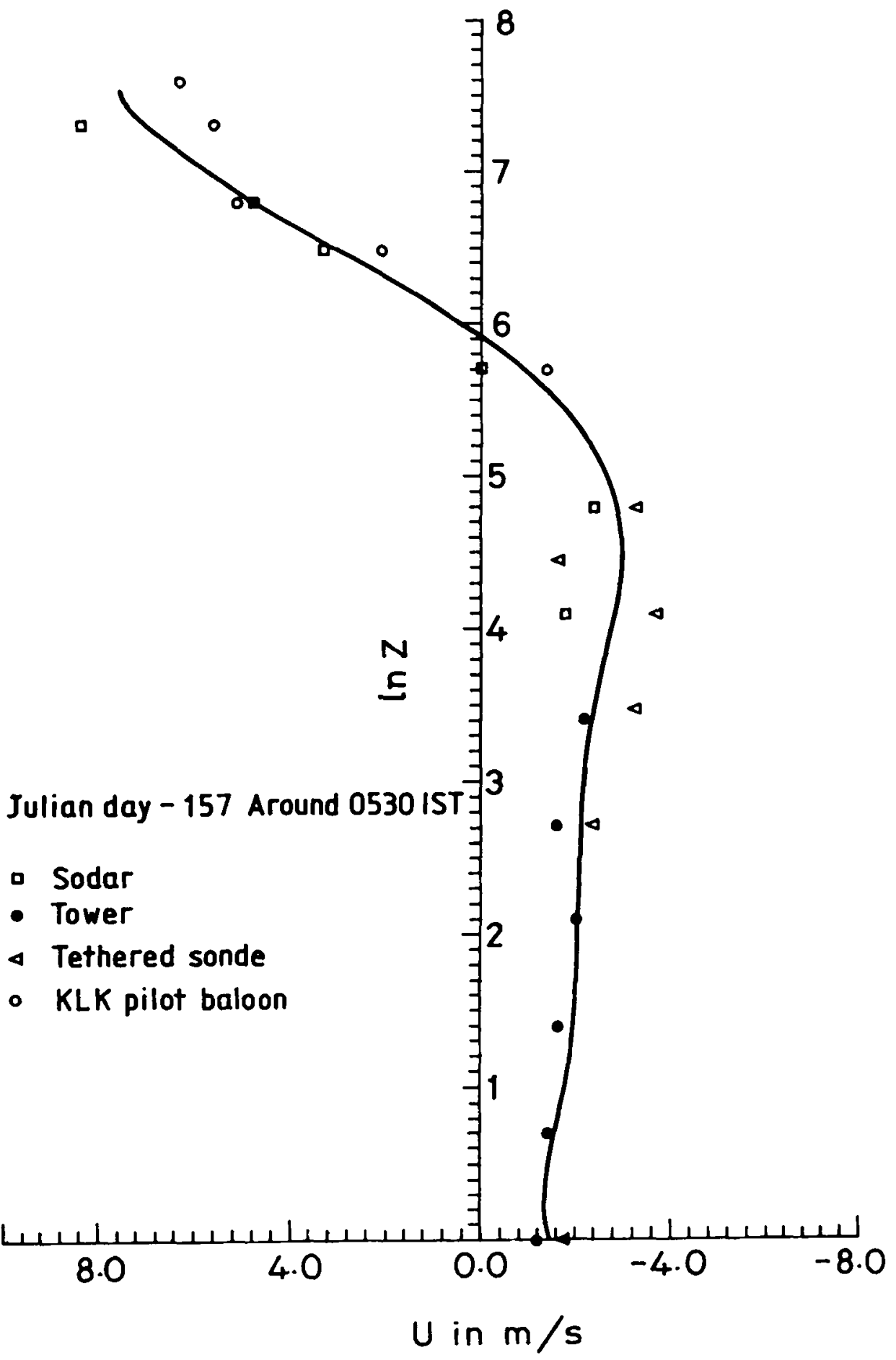

Figure 1(a). Mean vertical profile of zonal wind. 


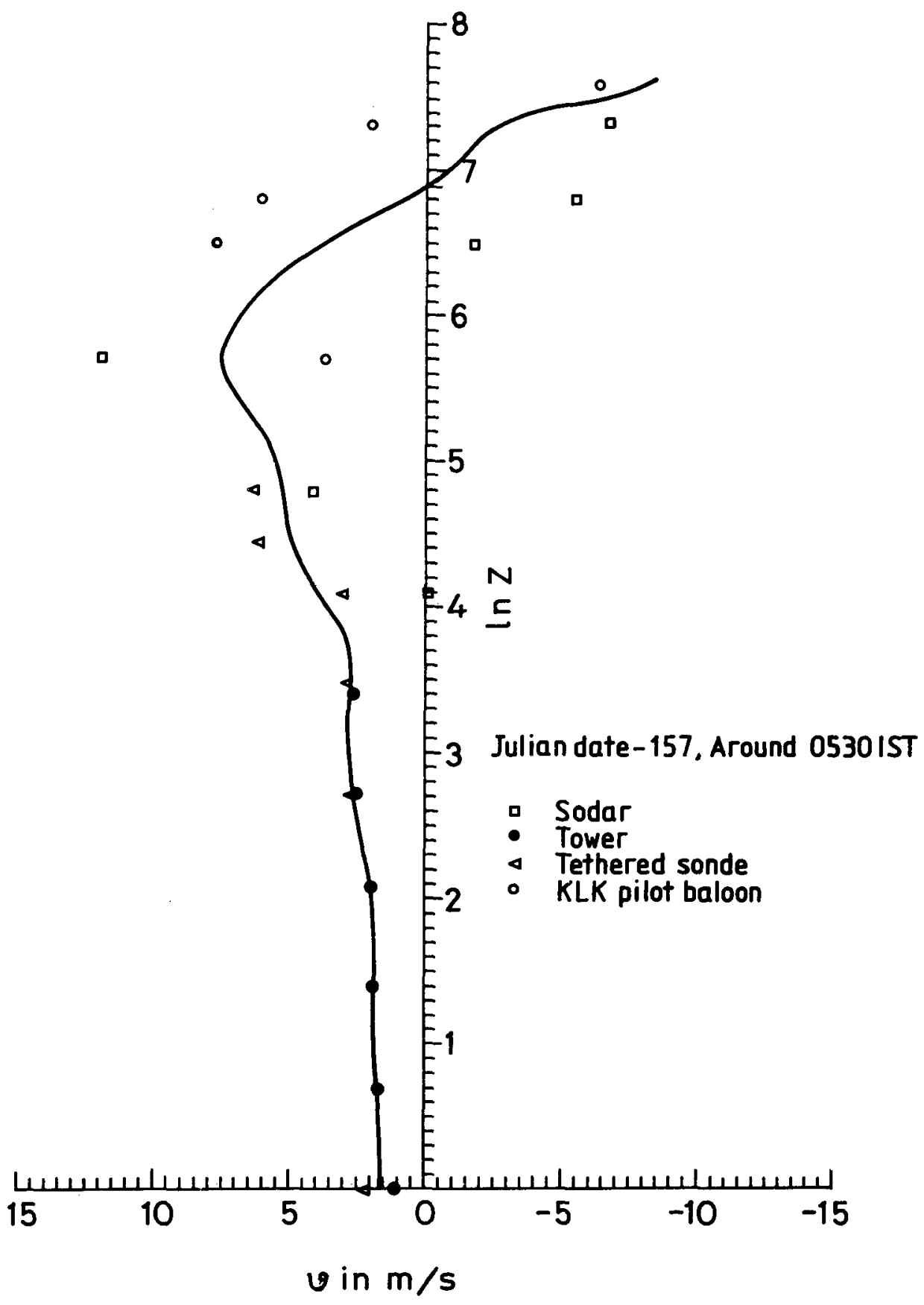

Figure 1(b). Mean vertical profile of meridional wind.

\subsection{Pilot balloon data from Kalaikunda}

In general pilot balloon observations were taken during four synoptic hours i.e., 00 UTC, 06 UTC, 12 UTC and 18 UTC. Although the observations were taken from 
Kalaikunda Air Base, the upper wind data may be taken as almost representative for Kharagpur which is within a distance of $5 \mathrm{~km}$.

It should be noted that all the four above-mentioned sensors provided wind data though the averaging periods were different. Besides, the height range of the tower and kytoon overlapped but the sodar ranges were much beyond; and lastly pilot balloon and the sodar data overlapped over a range of height, though the pilot balloon soared to a much greater height. Thus the wind data available from four different sensors have overlapping ranges but different averaging times.

However, temperature data were available only from the tower and kytoon, so these comparisons remain limited to the tower height.

\subsection{Ceilometer data from $K L K$}

The laser ceilometer was operated from the KLK Air Base at one-hour intervals during day-time. Data were available from 0700 IST to 1800 IST. These data provide the low level cloud-base height for the present study. The ceilometer cloud-base height at a particular hour is actually the mean of the two readings taken in a 10-minute interval.

Table 1. Dry bulb temperature in ${ }^{\circ} \mathrm{C}$.

\begin{tabular}{|c|c|c|c|c|c|}
\hline Date & $\begin{array}{l}\text { Time } \\
\text { (IST) }\end{array}$ & $\begin{array}{l}\text { Height } \\
\text { (metre) }\end{array}$ & Tower & Kytoon & $\begin{array}{c}\text { Kalaikunda } \\
\text { surface }\end{array}$ \\
\hline $\begin{array}{l}04.06 .90 \\
(155)\end{array}$ & 0606 & $\begin{array}{l}01 \\
10 \\
26 \\
30 \\
41\end{array}$ & $\begin{array}{c}27 \cdot 38 \\
- \\
- \\
27 \cdot 17 \\
-\end{array}$ & $\begin{array}{c}- \\
27.08 \\
26.91 \\
\overline{26.81}\end{array}$ & $28 \cdot 0$ \\
\hline $\begin{array}{l}05.06 .90 \\
(156)\end{array}$ & 0627 & $\begin{array}{l}01 \\
12 \\
30 \\
37\end{array}$ & $\begin{array}{c}27 \cdot 82 \\
- \\
27 \cdot 88 \\
-\end{array}$ & $\begin{array}{c}27.84 \\
27.69 \\
- \\
27.5\end{array}$ & $27 \cdot 6$ \\
\hline $\begin{array}{l}06.06 .90 \\
(157)\end{array}$ & 0539 & $\begin{array}{l}01 \\
15 \\
30 \\
32\end{array}$ & $\begin{array}{c}25 \cdot 38 \\
- \\
24 \cdot 8 \\
-\end{array}$ & $\begin{array}{c}24.78 \\
24.73 \\
- \\
24.6\end{array}$ & $25 \cdot 0$ \\
\hline $\begin{array}{l}07.06 .90 \\
(158)\end{array}$ & 0530 & $\begin{array}{l}01 \\
05 \\
18 \\
30 \\
42\end{array}$ & $\begin{array}{c}25.61 \\
- \\
-- \\
25.91 \\
-\end{array}$ & $\begin{array}{c}- \\
25.89 \\
25.55 \\
- \\
25.52\end{array}$ & $26 \cdot 4$ \\
\hline $\begin{array}{l}09.06 .90 \\
(160)\end{array}$ & 0554 & $\begin{array}{l}01 \\
09 \\
29 \\
30 \\
36\end{array}$ & $\begin{array}{c}27 \cdot 52 \\
- \\
- \\
27.63 \\
-\end{array}$ & $\begin{array}{c}- \\
27 \cdot 1 \\
26 \cdot 96 \\
- \\
26 \cdot 90\end{array}$ & $28 \cdot 0$ \\
\hline
\end{tabular}




\section{Analysis of wind and temperature data}

Both zonal $(u)$ and meridional $(v)$ components have been studied taking data from all four platforms. A representative profile of each component is presented in figure 1 (a and b) respectively. In fact, the mean profile during all these days is always a smooth curve, though the curve is drawn step-wise for each layer taking mean of all the available data within that layer.

Considering the profiles on all the days from June 4th -9 th, 1990, some general conclusions may be drawn:

- A low level jet existed at around $300 \mathrm{~m}$ level in sodar data during the morning hours on all these days. The jet velocity never fell below $12 \mathrm{~m} / \mathrm{s}$ and has a dominant southerly component. Above the jet-level, a strong veering of wind exists.

- Around $300 \mathrm{~m}$ the first pilot balloon data are available, and on some occasions the kytoon reaches a height around $350 \mathrm{~m}$. But from these platforms there is no concrete evidence for the existence of the low level jet on all these days.

- Compared to the tower data, the kytoon always gives a more negative $u$-component. So, the easterly component of wind dominates in the kytoon.

- Looking at the sodar and kytoon data structures one can conclude that the $v$ component of the sodar wind starts going above the corresponding component of the kytoon wind at a height which varies from $100 \mathrm{~m}$ to $200 \mathrm{~m}$. However, one should remember that the averaging times for different platforms are completely different. Pilot balloon data are instantaneous, but the averaging time for the tower data is 3 minutes, for the kytoon it is almost instantaneous; on the other hand it goes to one hour in case of the sodar.

Table 1 shows good agreement in the temperature profile between tether sonde and tower data, though the tower temperatures are in general slightly higher. It has already been pointed out that there exists a sharp variation in temperature gradient in the

Table 2. Fourteen days comparison of sodar-reported inversion depth and back-scatter echo intensity.

\begin{tabular}{lccc}
\hline $\begin{array}{l}\text { Julian } \\
\text { day }\end{array}$ & $\begin{array}{c}\text { Sodar sounding } \\
\text { period in IST }\end{array}$ & $\begin{array}{c}\text { Sodar-reported } \\
\text { inversion depth }\end{array}$ & $\begin{array}{c}\text { Sodar-reported back- } \\
\text { scattered echo intensity }\end{array}$ \\
\hline 144 & $0600-0700$ & $150 \mathrm{~m}$ & $1 \mathrm{st} \ldots 150 \mathrm{~m}$ \\
145 & $0600-0630$ & $390 \mathrm{~m}$ & $1 \mathrm{st} \ldots 200 \mathrm{~m}$ \\
146 & $0544-0600$ & $210 \mathrm{~m}$ & $1 \mathrm{st} \ldots 210 \mathrm{~m}$ \\
155 & $0600-0700$ & $210 \mathrm{~m}$ & $1 \mathrm{st} \ldots 210 \mathrm{~m}$ \\
156 & $0600-0700$ & $210 \mathrm{~m}$ & $1 \mathrm{st} \ldots 200 \mathrm{~m}$ \\
160 & $0600-0700$ & $240 \mathrm{~m}$ & $1 \mathrm{st} \ldots 230 \mathrm{~m}$ \\
168 & $0500-0600$ & $90 \mathrm{~m}$ & $1 \mathrm{st} \ldots 87 \mathrm{~m}$ \\
168 & $1700-1800$ & $660 \mathrm{~m}$ & $1 \mathrm{st} \ldots 210 \mathrm{~m}$ \\
& & & $2 \mathrm{nd} \ldots 640 \mathrm{~m}$ \\
169 & $0500-0600$ & $600 \mathrm{~m}$ & $1 \mathrm{st} \ldots 140 \mathrm{~m}$ \\
170 & $0519-0600$ & $90 \mathrm{~m}$ & $1 \mathrm{st} \ldots 100 \mathrm{~m}$ \\
170 & $0524-0600$ & $180 \mathrm{~m}$ & $1 \mathrm{st} \ldots 120 \mathrm{~m}$ \\
172 & $0511-0607$ & $450 \mathrm{~m}$ & $1 \mathrm{st} \ldots 400 \mathrm{~m}$ \\
174 & $0518-0600$ & Not available & $1 \mathrm{st} \ldots 400 \mathrm{~m}$ \\
& & & $2 \mathrm{nd} \ldots 1040 \mathrm{~m}$ \\
175 & $0535-0600$ & Not available & $1 \mathrm{st} \ldots 120 \mathrm{~m}$ \\
\hline
\end{tabular}



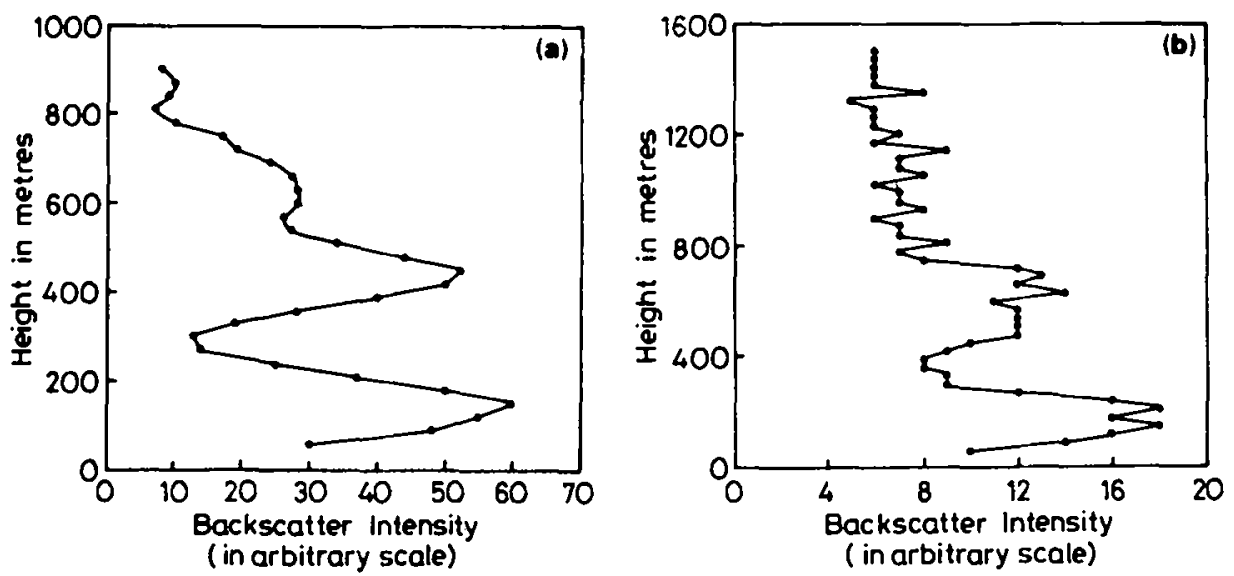

Figure 2. Vertical profile of back-scatter echo intensity as provided by sodar on (a) Julian day 144, 0600-0700 IST and (b) Julian day 168, 1700-1800 IST.

tower data (Pradhan et al 1994a) over $30 \mathrm{~m}$ height. Hence in the present study that sharp variation has been neglected by taking the temperature at the lowest level $(1 \mathrm{~m})$ and at the highest level $(30 \mathrm{~m})$ only. Tether sonde data are being presented up to a height which is nearest to but above $30 \mathrm{~m}$ height. Incidentally KLK surface temperature data are included in the last column of table 1 . From the table it is evident that the temperature data from different platforms are compatible.

It is also evident from table 1 that kytoon shows local surface instability on all the days. But the tower shows instability on Julian days 155 and 157 and the situation is nearly stable on all other days. Again, the lapse rate obtained from the tower data is quite comparable with that obtained from the tether sonde data on day 155. But on day 157, the lapse rate from the tower is appreciably higher. The magnitude on day 157 is higher than even the dry adiabatic lapse rate. It should be mentioned that this super-adiabatic situation has been observed in some cases. This situation is not at all unusual specially in the surface layer (Webb 1982).

It should be pointed out here that such irregularity in the thermal structure exists in many cases when the entire data set is analysed.

\section{Some observations from sodar data only}

The sodar provides the back-scatter echo intensity (in arbitrary units) from various ranges above the ground level, and also an inversion height with the help of an in-built algorithm. In the present work the vertical profile of the back-scatter echo intensity $\left(I_{v}\right)$ is drawn and its peaks are compared with the inversion height (Roy 1994).

It is found that in eighty per cent of the cases the first distinct peak of back-scatter intensity coincides with the inversion height but in the rest (twenty per cent) the match is distinctly better with the second peak. In the latter cases, the first peak is apparently due to some noise.

In table 2, fourteen sets of data are presented covering about a month starting from May 24th, 1990. The second peak of back-scatter intensity is indicated in the table 


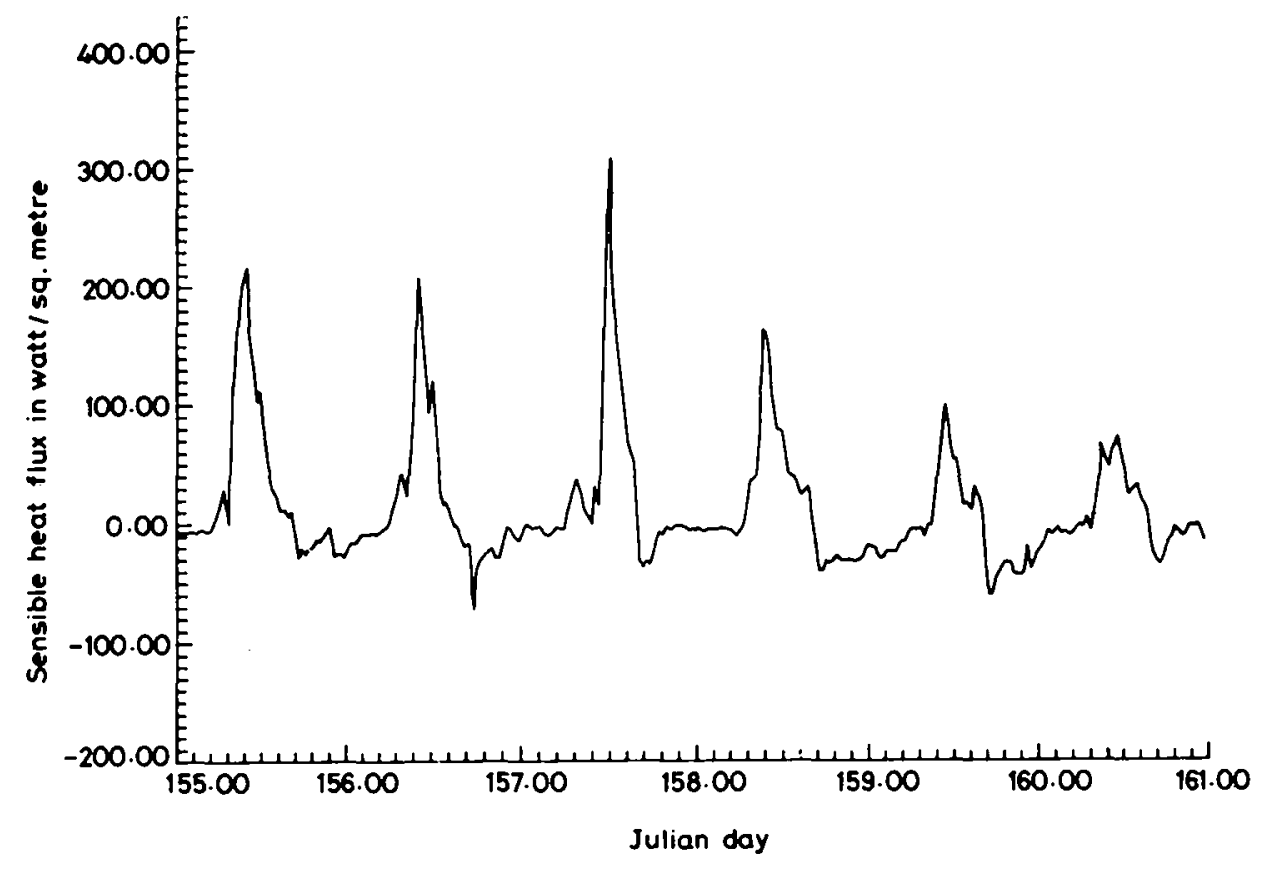

Figure 3. Time series of surface sensible heat flux from Julian day 155 to 160.

where it coincides with the sodar-reported inversion depth. All the data sets except one are during morning hours. Two representative vertical profiles of back-scatter echo intensity are being presented in figure $2(a$ and $b$ ). The inversion height given by the sodar system coincides with the first peak in figure $2(a)$ and the second peak in figure 2(b).

\section{Synoptic situations, surface parameters and inter-play of low level cloud and inversion height}

One can evaluate surface parameters like sensible heat flux, momentum flux and scaling temperature using the flux-profile and similarity relations of wind and temperature (Pradhan et al 1994b). The variations of the sensible heat flux and the momentum flux for the period of study are presented in figures 3 and 4 . It should be noted that in these figures the day is indicated by Julian day and starts fron 0000 IST and ends at 2400 IST.

The inter-relation of the cloud-base height from the ceilometer and the inversion height from the sodar are presented in figure 5. It is interesting to note that on June 4th, 5th and 6th (day 155 to 157) the cloud-base remains within the inversion height for varying durations of time. It is also to be noted that on those three days the maximum of the sensible heat flux also shoots up. In table 3, the time of occurrence of the maximum instability, the momentum flux and the sensible heat flux is presented. Besides, information about the temporal growth of the inversion height is also included in the 'remarks' column. 


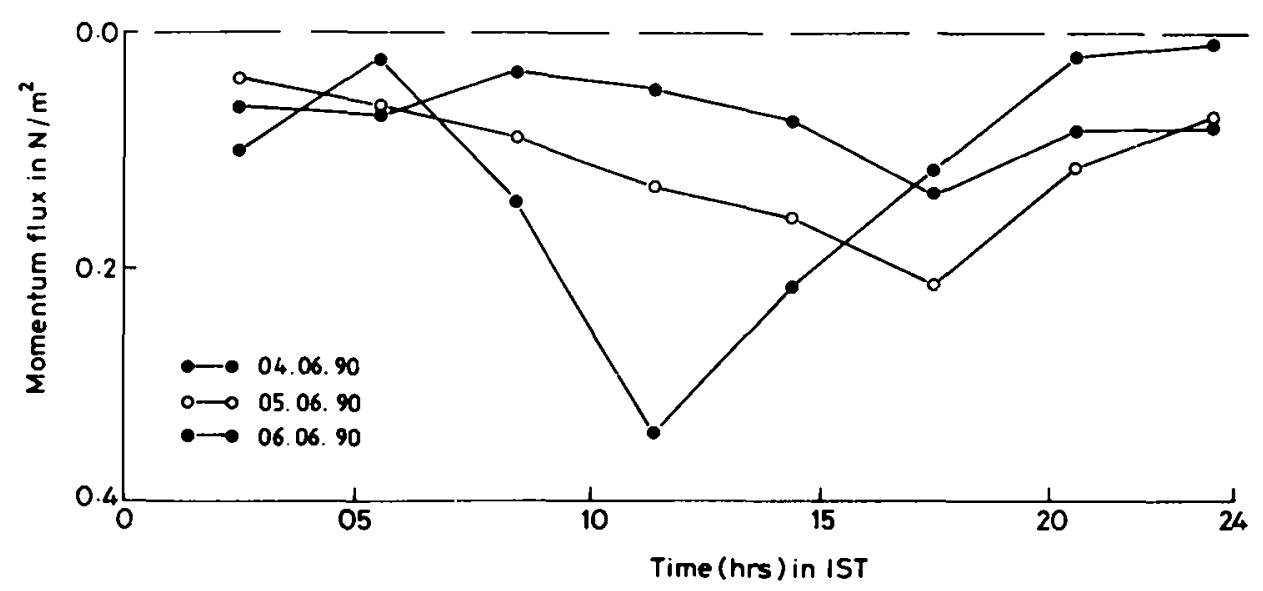

Figure 4. Diurnal variation of momentum flux from Julian day 155 to 157.

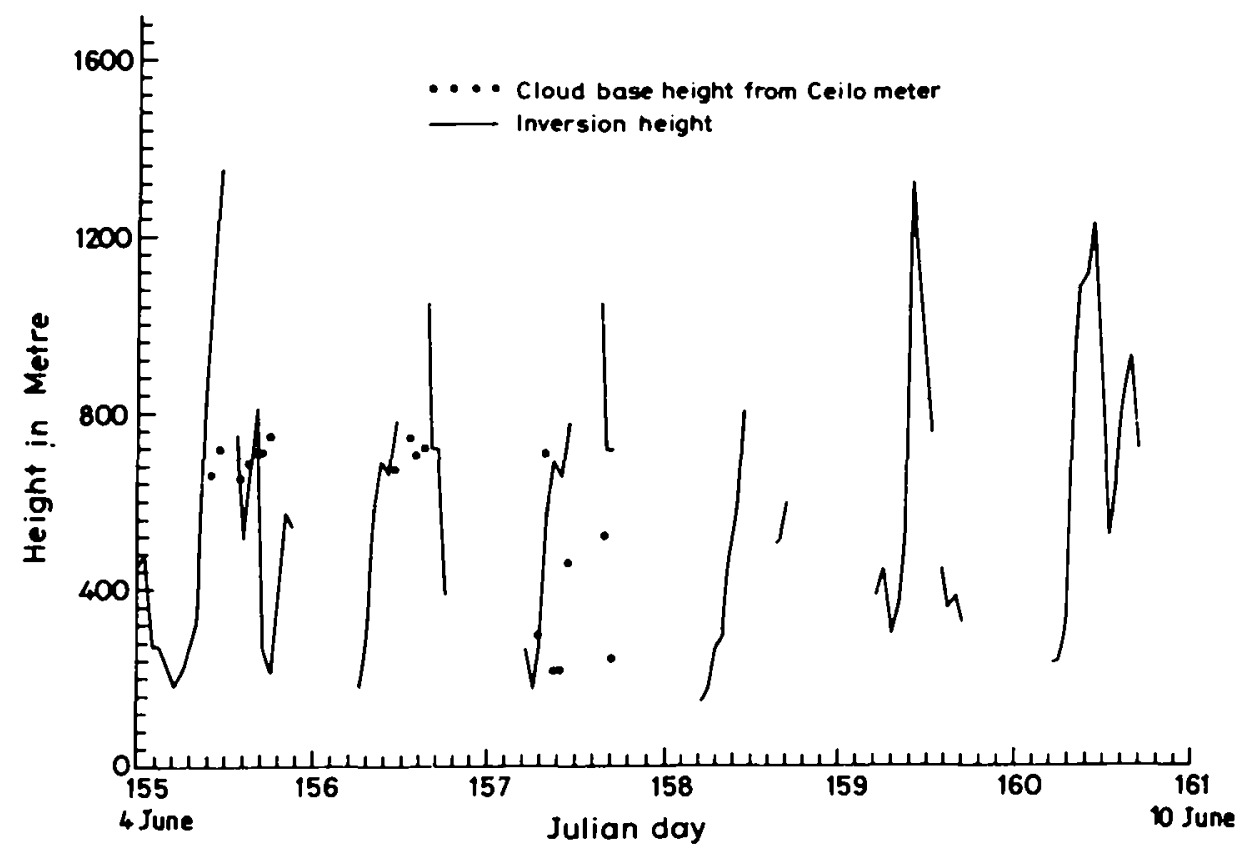

Figure 5. Simultaneous presentation of inversion depth obtained from sodar and lowest cloud-base height from laser ceilometer.

One finds that the maximum of heat flux always occurs earlier than the maximum of the inversion height. In fact the inversion height rises in the wake of rising heat flux; whenever the heat flux rises sharply, the inversion height also shoots up. But it also happens that on the three days under consideration the inversion height is no longer available from the sodar after it reaches a sufficiently high value. There are then two possibilities. First, the inversion height may rise above $1500 \mathrm{~m}$ which is the maximum range of the sodar being used; second, it might also happen that the inversion may not exist at all. 
Table 3. Unstable condition. Time (in IST) of occurrence of maximum value in diumal variation.

\begin{tabular}{|c|c|c|c|c|c|}
\hline $\begin{array}{l}\text { Julian } \\
\text { day }\end{array}$ & $\begin{array}{l}\text { Max. of } \zeta \\
\text { at hrs. }\end{array}$ & $\begin{array}{l}\text { Max. of } \tau \\
\text { at hrs. }\end{array}$ & $\begin{array}{l}\text { Max. of } \mathrm{H} \\
\text { at hrs. }\end{array}$ & $\begin{array}{c}\text { Maximum inversion } \\
\text { height at hrs. }\end{array}$ & Remarks \\
\hline 155 & $\begin{array}{l}0930 \\
\text { to } \\
1000\end{array}$ & $\begin{array}{l}1600 \\
\text { to } \\
1630\end{array}$ & $\begin{array}{c}0930 \\
10 \\
1000\end{array}$ & $1100-1200$ & $\begin{array}{l}\text { Inversion height starts rising from } \\
0800-0900 \text { hrs. Maximum value } \\
\text { is } 1350 \mathrm{~m} \text {. No inverted height is } \\
\text { available from } 1200-1400 \mathrm{hrs} \text {. }\end{array}$ \\
\hline 156 & $\begin{array}{l}1000 \\
10 \\
1030\end{array}$ & $\begin{array}{l}1430 \\
10 \\
1530\end{array}$ & $\begin{array}{c}1000 \\
10 \\
1030\end{array}$ & $1524-1600$ & $\begin{array}{l}\text { Inverted height starts rising from } \\
0800-0900 \text { hrs. and reaches maxi- } \\
\text { mum value of } 1050 \mathrm{~m} \mathrm{AGL} \text {. No } \\
\text { inverted height is available from } \\
1200-1524 \mathrm{hrs} \text {. }\end{array}$ \\
\hline 157 & $\begin{array}{l}1200 \\
10 \\
1230\end{array}$ & $\begin{array}{l}1130 \\
10 \\
1200\end{array}$ & $\begin{array}{c}1200 \\
\text { to } \\
1230\end{array}$ & $1524-1600$ & $\begin{array}{l}\text { Awake of inverted height starts from } \\
0800-0900 \text { hrs. Maximum value } \\
\text { is } 1050 \mathrm{~m} \text { AGL. No inverted height } \\
\text { is available from } 1200-1524 \mathrm{hrs} \text {. }\end{array}$ \\
\hline 158 & $\begin{array}{l}0930 \\
\text { to } \\
1000\end{array}$ & $\begin{array}{l}1600 \\
10 \\
1630\end{array}$ & $\begin{array}{c}0930 \\
\text { to } \\
1000\end{array}$ & $1100-1200$ & $\begin{array}{l}\text { Awake of inverted height starts from } \\
0800-0900 \mathrm{hrs} \text {. Maximum value is } \\
0810 \mathrm{~m} \text { AGL. No inverted height is } \\
\text { available from } 1200-1534 \mathrm{hrs} \text {. }\end{array}$ \\
\hline 159 & - & - & - & $1039-1100$ & $\begin{array}{l}\text { Availability of surface layer data is } \\
\text { scattered in morning time and up to } \\
1130 \mathrm{hrs} \text {. Maximum value of in- } \\
\text { verted height is } 1320 \mathrm{~m} \text {. No in- } \\
\text { verted height is available from } \\
1200-1406 \mathrm{hrs} \text {. }\end{array}$ \\
\hline 160 & $\begin{array}{l}1030 \\
\text { to } \\
1100\end{array}$ & $\begin{array}{l}1400 \\
\text { to } \\
1430\end{array}$ & $\begin{array}{c}1130 \\
\text { to } \\
1200\end{array}$ & $1100-1200$ & $\begin{array}{l}\text { Inverted height starts rising from } \\
0700-0800 \text { hrs. Maximum value } \\
\text { is } 1230 \mathrm{~m} \text { AGL. No inverted height } \\
\text { is available throughout the un- } \\
\text { stable period. }\end{array}$ \\
\hline
\end{tabular}

It is known that during unstable conditions the boundary layer is usually capped by an elevated inversion layer, and then one may accept that the depth of the boundary layer may be approximated by the inversion depth. In a stable situation, however, the inversion height signifies the top of the ground-based inversion. Many boundary layer meteorologists accept the concept that the inversion height gives the boundary layer height. But one can always claim that in either case the inversion height is closely related to the boundary layer depth.

Thus, during June 4th - 6th, 1990 one can claim that the cloud penetrated the boundary layer and it is extremely important to check the peculiarities of these days.

Lastly, one can look at the synoptic situation and attempt to understand the impact of the surface parameters on the synoptic features and the inter-play between the low-lying clouds and the boundary layer depth. During the period of study, there were mesoscale phenomena like thunderstorm developments which are mentioned here, but 

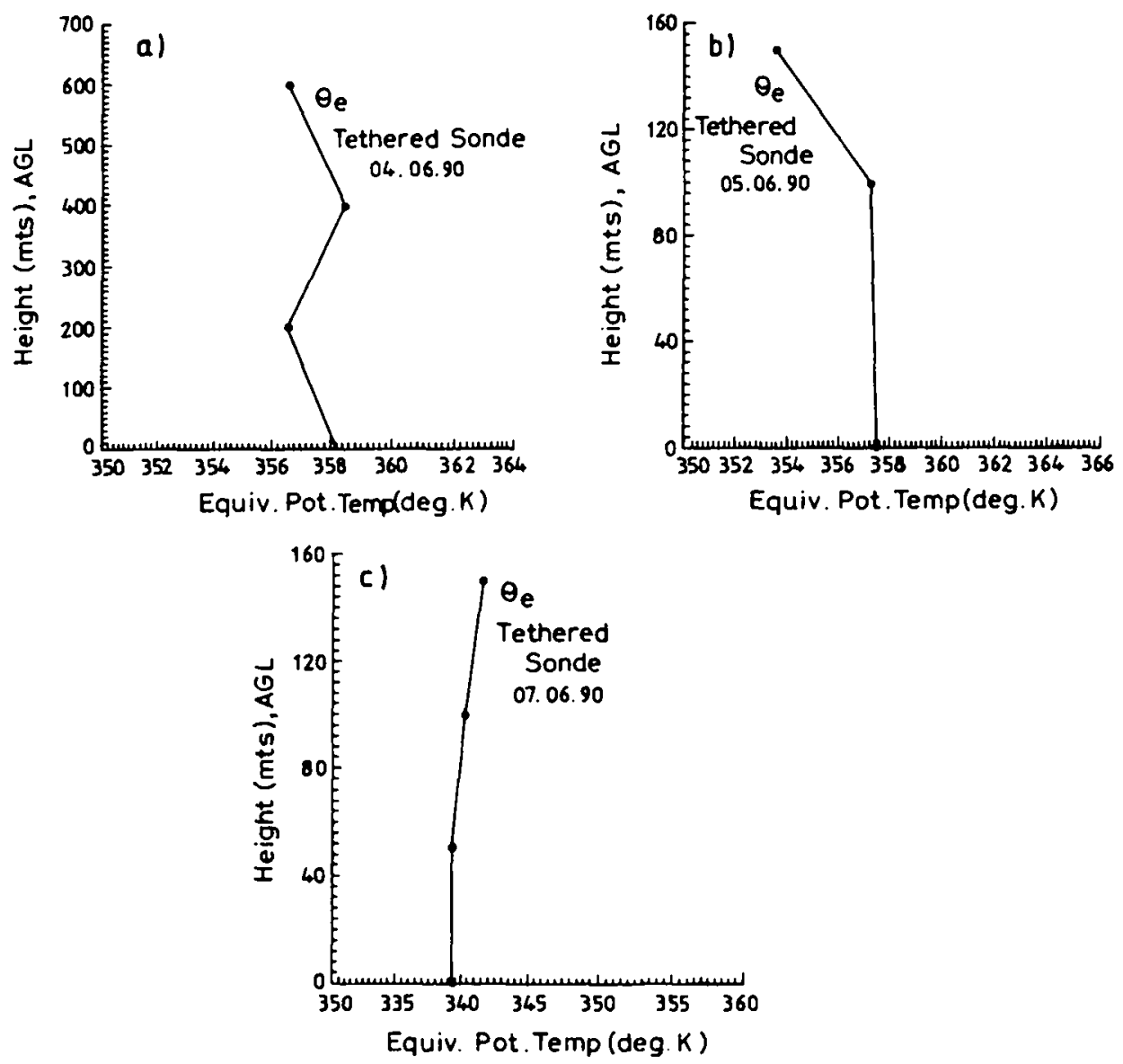

Figure 6. Vertical profile of equivalent potential temperature on Julian day (a) 155; (b) 156; and (c) 158 obtained from the morning flight of tether sonde.

the inter-relation between these events and the surface parameters are discussed elsewhere (Pradhan et al 1994b).

Incidentally, the period of the present study involved some atmospheric systems. Synoptically, from June 4 th -7 th, there were middle and lower tropospheric cyclonic circulations over west central Bay of Bengal. On June 6th (day 157) a sub-synoptic cyclonic circulation centred over Gangetic West Bengal, after June 7th, the system dissipated. A low pressure system on June 10th lay over the north and west-central Bay of Bengal.

Incidentally, the tether sonde data provide the overall thermal structure of the atmosphere up to the sensed height. The thermal stability may be understood from the vertical profile of potential and equivalent potential temperature.

The inter-play of various features may be better realized if those features are compared day-by-day.

On June 4th (day 155), the cloud-base was below the inversion height at 1000 IST, 1100 IST and 1600 IST. However, inversion height data were not available from 1200 to 1420 IST. Again, ceilometer data were not available beyond 1800 IST. The average cloud-base height was near $700 \mathrm{~m}$. Cumulus and strato-cumulus types were observed. 
The inversion height varied from $800 \mathrm{~m}$ to $1400 \mathrm{~m}$, when low clouds penetrated the inversion height.

There was surface convective instability since the morning as revealed by the tether sonde data (figure 6a). The sensible heat flux was high and the diurnal maximum was the second highest of the six days of time series presented (figure 3 ). As the momentum flux was low throughout the day (figure 4), the surface-scaling temperature (sensible heat flux divided by the square root of the momentum flux) was found to reach the maximum of the six days concerned. The maximum surface instability $\zeta$ (Stull 1988) was nearly $-5 \cdot 0$.

On the same day, a thunderstorm was reported at Kharagpur with a precipitation of $4.3 \mathrm{~mm}$ in the period between 2130 and 2359 IST.

On June 5th (day 156), the low cloud-base was distinctly below the inversion height at 1100 IST and 1600 IST. The inversion height data were not available from 1200 to 1524 IST. Average cloud-base height was nearly $750 \mathrm{~m}$, whereas the inversion height varied from $750 \mathrm{~m}$ to $1000 \mathrm{~m}$. There was a ground-based stable layer in the morning. This is inferred from a profile of the equivalent potential temperature (figure $6 \mathrm{~b}$ ). The surface sensible heat flux is high but the diurnal maximum was less than on the previous day and the scaling temperature shows a decreasing trend. The maximum surface instability $\zeta$ was -0.69 .

There was a widespread thunderstorm over Gangetic West Bengal, the Bihar plateau and many parts of northeast India. The thunderstorm struck Kharagpur at about 2220 IST on June 5th and persisted till 0010 IST of the next day with a precipitation of $6.8 \mathrm{~mm}$.

On June 6th (day 157), for most of the time of the ceilometer observation, the low cloud was found to have penetrated the inversion height. The average cloud-base height of the penetrating low cloud was as low as $300 \mathrm{~m}$, whereas the corresponding inversion height varied from $500 \mathrm{~m}$ to $1000 \mathrm{~m}$. As indicated previously, a local convergence field developed over Gangetic West Bengal during the afternoon hours. In its wake, the momentum flux shot up to the highest value (figure 4) during the entire period of observation. Associated with this, the highest sensible heat flux (figure 3) is also found to occur, in spite of the scaling temperature showing a further downward trend in its diurnal maximum. Another notable feature was that whereas on all other days the momentum flux maximum occurred in the afternoon, on this day it occurred during the interval 1130 IST to 1200 IST. The maximum diurnal instability was $-0 \cdot 15$.

In fact on this day, the cloud was so low that no pilot balloon flight could be undertaken.

After June 6th, the symptoms of dissipation of the cyclonic vorticity in the Bay of Bengal were appearing. In fact no low cloud overhead at KLK Air Base was recorded by the ceilometer during June $7 \mathrm{th}-9 \mathrm{th}$. Sensible heat flux started to fall continuously. The diurnal maximum on June 7 th was even less than that on June 5 th. The diurnal maximum of momentum flux fell from the June 6th value by about $25 \%$ and then settled at a steady value because of a strong wind field during June 7 th -9 th. So scaling temperature fell further though the maximum instability during this period did not differ much from the June 6th magnitude.

\section{Conclusions}

One can conclude that the temperature and wind field data obtained from different sources at and around Kharagpur have overall compatibility. The most notable feature 
is the presence of a low level southerly jet in the morning hours sensed by the sodar at around $300 \mathrm{~m}$ above ground.

The inversion height supplied by the Aerovironment sodar and the first peak observed in the vertical profile of the back-scatter intensity are in general, closely related. However, in some cases the second peak is better correlated with the inversion height.

It seems that the synoptic features and the surface parameters as well as the inter-relation of the low cloud formation with the atmospheric boundary layer have a close linkage. It is evident from the analysis of these few days that whenever the low clouds can penetrate the boundary layer or inversion height, the surface sensible heat flux rises appreciably. On the other hand such a situation dominates whenever there is a convergence field, on either the synoptic or the sub-synoptic scale. In the presence of convergence, momentum flux shoots up because of high shear in the wind field. Thus, the sub-synoptic or synoptic scale convergence modulates the inversion height and the presence of cloud-base within the inversion height, which in turn modulates the sensible heat and momentum fluxes. However, it must be mentioned that to come to a firm conclusion, one must undertake more extensive studies of similar situations.

One should note that the monsoon advanced over northeast India on June 4th and the onset for Calcutta was declared on June 6th (Gupta 1990). But it did not advance much further beyond that date (Gupta 1990). This is evidently supported by the usual pattern of variation of the sensible heat flux as well as the inversion height as on an undisturbed day. Again this is supported by the rainfall distribution over Kharagpur (Pradhan et al 1994b). Apparently the monsoon over Kharagpur advanced with the depression which intensified from a low to this state over the Bay of Bengal on June 13 th and crossed land on June 14th.

Lastly, it should be mentioned that on June 4th, the boundary layer was of the free convective type (as is evident from high scaling temperature and high negative value of $\zeta$ ), but with the passage of time it converted first to a mixed convective type and then finally settled towards a forced convective situation (Thom 1975).

\section{Acknowledgements}

The authors are thankful to DST, Govt. of India for the sanction of a research project and the present work is a part of that project.

\section{References}

Gupta M G 1990 MOCC Brief report, India Meteorological Department (New Delhi, India)

Pradhan R. De U K and Sen P K 1994 a Estimation of roughness length at Kharagpur micrometeorological tower site during monsoon onset of 1990; Mausam 45 184-186

Pradhan R, De U K and Sen P K 1994 b Surface sensible heat flux over a deep moist convective region and its interplay with synoptic and mesoscale features; Proc. Indian Acad. Sci. (Earth Planet. Sci.) 103 353-367

Roy B 1994 Doppler acoustic sounding studies of some atmospheric boundary processes in a moist convective region; Ph.D. Thesis submitted to Jadavpur University, Calcutta (India) 248 pages

Stull R B 1988 An introduction to boundary-layer meteorology (Kluwer Academic publishers) pp 180-183

Thom A S 1975 Momentum. mass and heat exchange of plant communities, vegetation and the atmosphere. Principles, (ed) J L. Montcith (London: Academic Press) $157-109$

Webb E K 1982 Profile relationships in the superadiabatic surface layer; Q. J. R. Meteorol. Soc., 108661 